\title{
11. ENTRE O ALIENISTA E O ALIENADO: O JUIZ E A NATURALIZAÇÃO DO ADOLESCENTE INFRATOR
}

\author{
Caroline Santos de Viera ${ }^{1}$
}

\begin{abstract}
Resumo: O presente artigo elabora um diálogo entre o Conto O Alienista de Machado de Assis e as práticas verificadas nos juizados da infância e da juventude no Brasil. Faz-se um comparativo entre os atos de Simão Bacamarte, o médico que buscava, à qualquer custo, o estudo e a cura da loucura, e o juiz, ao apreciar processo de apuração de ato infracional. Conforme discorreremos, a aplicação da medida socioeducativa de internação vem sendo aplicava de forma massiva, com apoio na naturalização do comportamento criminoso.
\end{abstract}

Palavras-chave: O Alienista, o Juiz, naturalização do criminoso

\begin{abstract}
This paper develops a dialogue between the Alienist The Tale of Machado and practices observed in the courts of childhood and youth in Brazil. It is a comparison between the acts of Simon Blunderbuss, the doctor who was seeking for any cost, the study and cure of madness, and the judge, to enjoy the process of investigating the infraction. As we will discuss the application of the educational measure of hospitalization has been applied on a massive scale, with support in the naturalization of criminal behavior.
\end{abstract}

Keywords: the psychiatrist, the judge, the criminal naturalization

\section{Introdução}

O presente artigo pretende analisar criticamente o discurso de finalidade pedagógica invocado pelos juízes para a imposição da medida socioeducativa de internação aos adolescentes infratores. Lançando mão do conto "O Alienista", de Machado de Assis, sobre os "loucos" da Casa Verde ${ }^{2}$, construída e dirigida pelo Dr. Simão Bacamarte, que identificava a loucura como o comportamento diferente, desviante do padrão de normalidade aceito pelo cientista, o que traz recordações muito próximas às práticas da Justiça da Infância e da Juventude.

\footnotetext{
${ }^{1}$ Docente do Curso de Pós-Graduação em Direito Processual da UNIVATES e do Curso de Pós-Graduação em Direito Penal e Processo Penal do IMED, bem como é professora titular de Direito Processual Civil da Fundação Escola Superior da Defensoria Pública do Rio Grande do Sul (FESDEP) Mestre em Ciências Criminais, Especialista em Ciências Penais, Bacharel em Direito pela PUCRS. Advogada. Email: carolviera@outlook.com.

2 "A Casa Verde foi o nome dado ao asilo, por alusão à cor das janelas, que pela primeira vez apareciam verdes em Itaguaí. Inaugurou-se com imensa pompa; [...] Muitos dementes já estavam recolhidos...”. p. 41/42.
} 
Ocorre que o médico, na sede de demonstrar e testar seus conhecimentos sobre a pisque humana, elegia dentre a população de Itaguaí, aqueles que considerava padecentes de alguma loucura, por apresentarem um comportamento diverso daquele considerado pelo mesmo como "normal". Para Simão Bacamarte, o homem seria redutível a um conceito, a um enquadramento psíquico que seria digno de estudo e cura.

A ânsia do médico e sua pretensão de totalidade eram tamanhas que objetificaram o ser humano, reduzindo seus pacientes a uma mera categorização psicológica, através do recurso ao discurso de legitimidade da Ciência $^{3}$, sob o pretexto de progresso e evolução, de estudar profundamente a loucura, os seus diversos graus, classificar-lhe os casos, descobrir enfim a causa do fenômeno e o remédio universal (ASSIS, 1998, p. 42).

Enquanto isso, o Direito da Criança e do Adolescente aponta para uma finalidade pedagógica da medida sócio-educativa de internação, defendendo que pretende diferenciarse da pena criminal como um sistema de respostas [...] à criminalidade infanto-juvenil, de modo que [...] defendesse a sociedade e estabelecesse mecanismo de intervenção [...] capaz de reverter o potencial criminógeno demonstrado pela prática da infração (DE PAULA, p. 13), o que demonstra fidelidade aos postulados da Criminologia Positivista ${ }^{4}$, e em verdade muito se assemelha às propostas punitivas do Direto Penal.

E nesse ponto vem o juiz da infância, na apreciação de um processo de apuração de ato infracional, assemelhar-se ao Alienista de Machado de Assis. Conforme pesquisa desenvolvida em sede de Mestrado, foi possível verificar que o juiz, ao proferir a sentença no processo de apuração de ato infracional, acaba recorrendo à pareceres técnicos a respeito da subjetividade do adolescente, para o fim de estabelecer a medida socioeducativa de internação.

\footnotetext{
${ }^{3}$ Assim o autor narrava: “Homem de ciência, e só de ciência, nada o consternava fora da ciência; se alguma coisa o preocupava naquela ocasião, se ele deixava correr pela multidão um olhar inquieto e policial, não era outra coisa mais do que a ideia de que algum demente podia achar-se ali misturado com a gente de juízo. ". (ASSIS, 1998, p. 47.).

${ }^{4}$ A Escola Positivista, de acordo com Elena Larrauri ao sistematizar as três premissas identificadas por David Matza do legado da escola Positivista ter-se-ia: A primazia do ator sobre o ato infrator (explicação da delinqüência baseada nas características físicas do individuo); a concepção do homem como um sujeito determinado por uma série de leis causais (determinação ao delito por causas alheias, externas e internas frente as quais não pode resisitir) e a criação de uma visão de que o delinqüente é um ser completamente distinto dos sujeitos normais (delinqüente como diferente, estranho). (LARRAURI, 2000. p. 17/19).
} 
Além disso, as sentenças nesta seara vem no sentido de aplicar a internação como primeiro recurso, ignorando a necessária excepcionalidade de sua aplicação, sob o pretexto de que a finalidade pedagógica é fruto de uma proteção ao adolescente, ou seja, para fazerIhes "o bem", pois assim como o Alienista, o juiz se apresenta como homem austero, Hipócrates forrado de Catão (ASSIS, 1998, p. 76).

2. A razão totalizante no itinerário das crianças e adolescentes: a falácia do discurso pedagógico e protetivo

O estabelecimento de uma finalidade pedagógica como resposta ao ato infracional não possui conformação com o princípio do respeito à condição peculiar de pessoa humana em desenvolvimento, sendo oposta ao paradigma de proteção especial que comporta apenas a medida socioeducativa como meio de redução das violências praticadas pelo Estado, para impedir a vingança privada [...] restringindo a manifestação do poder político estatal, que se dê de maneira arbitrária (sem limites) e violando os Direitos Fundamentais (ROSA, 2007, p. 72-73).

A finalidade pedagógica é contrária ao respeito à condição peculiar de pessoa em desenvolvimento porque pressupõe a ideia de modificação do sujeito, de intervenção na esfera subjetiva do adolescente, com sua normalização e adaptação, ou seja, objetificá-lo, o que se mostra igualmente inconstitucional.

O discurso de justificação pedagógica trabalha partindo do pressuposto de que a medida socioeducativa deva cumprir um papel formador do homem, visto que a personalidade do adolescente, por estar em construção seria mais suscetível a alterações (para não dizer conserto ou cura), e que o ato infracional cometido teria corrompido a personalidade do mesmo, rompendo com valores éticos e sociais.

Defender esta concepção significa retirar o papel da família, da escola e da sociedade no desenvolvimento humano, desrespeitar a autonomia do adolescente, como se o ato infracional por ele praticado revelasse uma natureza delinquente a ser extinta. Com efeito, a execução da medida socioeducativa deve ser pautada por princípios pedagógicos, todavia estes se fundamentam em assegurar os direitos fundamentais dos adolescentes de acordo com o paradigma da proteção especial. 
Não se pode conceder à lei, a um juiz ou mesmo ao sistema de justiça uma tarefa tão complexa quanto a tarefa de formação de um ser humano, por melhor que sejam as suas intenções, porque a complexidade deste processo ate então não fora desvendado pela ciência, talvez por sua natureza eminentemente humana. Destarte, é preciso muito além de uma boa proposta pedagógica para auxiliar (visto que o desenvolvimento humano é passível de interação e não de intervenção) no desenvolvimento de um ser humano.

Por este motivo deve-se entender a medida socioeducativa enquanto limite ao poder estatal e enquanto resposta ao ato cometido pelo adolescente, respeitados os seus direitos fundamentais. Assim explicitou Alexandre de Morais da Rosa:

\footnotetext{
...a resposta, como tal, deve ser objetiva e certa, rompendo-se com a indeterminação da medida socioeducativa e com o processo de canonização que lhe informa, visto que o adolescente, como o adulto, possui o Direito Fundamental de cometer atos infracionais e, comprovada a sua responsabilidade, arcar com o ônus de sua resposta. (ROSA, 2007, p. 203).
}

Ademais, existem estudos que indicam que alguns atos infracionais praticados podem ser considerados fenômenos normais do desenvolvimento humano. Nesta seara Juarez Cirino dos Santos trabalha sobre o tema, comentando acerca da fase denominada de peack-age, na qual o adolescente passaria para a idade adulta provavelmente abandonando eventual comportamento criminoso, o que se corrobora à luz da cifra oculta da criminalidade, na qual observamos que um reduzido número de jovens é selecionado pelo sistema, haja vista a imensa gama de atos infracionais sequer registrados (SANTOS, 2006).

\section{Razão técnica $X$ razão crítica: os laudos técnicos que legitimam a violência}

Entretanto o juiz, ao julgar processo de representação de adolescente pela prática de ato infracional, vincula-se de regra à laudos técnicos para determinar a privação de liberdade aos adolescentes condenados pela prática de ato infracional. Os laudos elaboram uma avaliação sobre a compatibilidade pessoal dos adolescentes para o cumprimento de medida em meio aberto ou fechado, de acordo com suas condições econômicas, sociais e familiares. 
A influência dos diagnósticos emitidos pelos pareceres técnicos sobre as decisões que determinavam a medida socioeducativa de internação é significativa, sendo que os juízes baseiam-se nos laudos para fundamentar a decisão pela medida em meio fechado. $O$ técnico avaliava a presença ou a ausência de autocrítica do adolescente em relação ao ato cometido, de acordo com o seu nível de remorso, ou culpa, pelo sofrimento das vítimas, de seus familiares, e até mesmo do seu próprio sofrimento.

Com base nesta avaliação, o técnico emite um parecer sobre a possibilidade de reincidência do examinado na prática de atos infracionais, o que permite ao julgador concluir pela necessidade de contenção do adolescente, pelo grau de periculosidade deste. Assim, a anamnese do adolescente infrator também passa pela análise de seus antecedentes, ainda que não criminais, nos exatos termos de Simão Bacamarte:

Compreende-se que, pela nova teoria, não bastava um fato ou um dito, para recolher alguém à Casa Verde; era preciso um longo exame, um vasto inquérito do passado e do presente. (ASSIS, 1998, p. 79).

$\mathrm{Na}$ apreciação do juiz o laudo técnico possui status científico que o guinda a um caráter de discurso de verdade, como já alertado por Michel Foucault ${ }^{5}$, visto que muitas das decisões em processos de apuração da prática de ato infracional apenas ratificam as conclusões provenientes dos pareceres técnicos, de forma a homologar o atestado de periculosidade.

Michel Foucault observa os efeitos jurídicos desta interação com o saber médico:

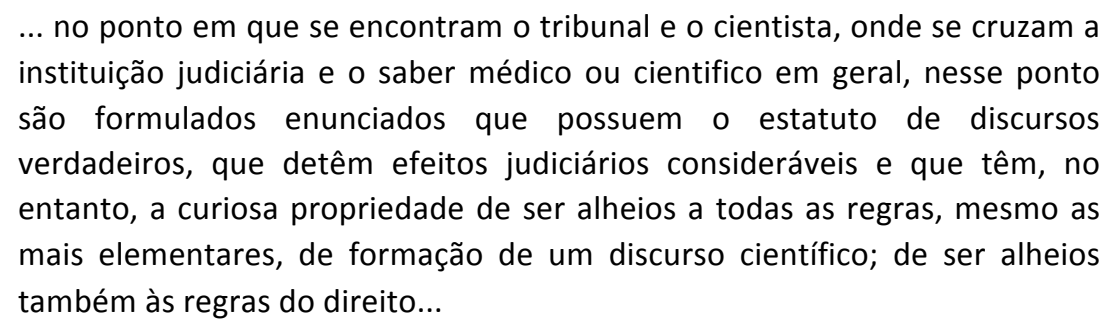

\footnotetext{
${ }^{5}$ Portanto, são discursos que têm, no limite, um poder de vida e de morte. Segunda propriedade: de onde lhes vem esse poder? Da instituição judiciária, talvez, mas eles detêm também do fato de que funcionam na instituição judiciária como discursos de verdade, discursos de verdade porque com estatuto cientifico, ou como discursos formulados, e formulados exclusivamente por pessoas qualificadas, no interior de uma instituição cientifica. (FOUCAULT, 2001. p. 8).
} 
A ciência médica, nesse caso, assim como o foi em Itaguaí, com as experiências do Dr. Simão Bacamarte, mostra que o essencial de seu papel é legitimar, na forma do conhecimento cientifico, a extensão do poder de punir a outra coisa que não a infração ${ }^{6}$.

Tanto o Dr. Simão Bacamarte, movido pelo discurso de progresso científico a qualquer custo, quanto o juiz da infância e da juventude, movido pelo discurso da internação-proteção, em virtude de uma suposta finalidade pedagógica, acabaram por naturalizar, o primeiro deles a loucura (com razão) e o segundo deles, o criminoso (como já foi realizado pela Escola Criminológica Positivista). Nesses termos Vera Regina Andrade Pereira já assinalou:

\begin{abstract}
Partindo do determinismo orgânico (anatômico-fisiológico) e psíquico do crime, Lombroso, valendo-se do método de investigação e análise próprio das Ciências naturais (observação e experimentação) procurou comprovar sua hipótese através da confrontação de grupos não-criminosos com criminoso dos hospitais psiquiátricos e prisões sobretudo do sul da Itália, pes- quisa na qual contou com o auxílio de Ferri, que sugeriu, inclusive, a denominação 'criminoso nato'. (ANDRADE, 1997, p. 64).
\end{abstract}

Os efeitos nefastos de justificar a internação na finalidade pedagógica estendem-se também ao não reconhecimento de garantias como a prescrição da pretensão Estatal de processar e julgar determinado ato infracional. Com base no discurso pedagógico e ressocializador jamais se esgotariam as chances de o Estado intervir na esfera subjetiva do indivíduo condenado pela prática de ato infracional, visto que se constrói a ideia de que se está a moldar um cidadão nos moldes socialmente aceitos, em nome de um bem maior que seria a paz e a segurança social, ou como o Alienista teria feito em nome da ciência ${ }^{7}$.

Alexandre Morais da Rosa alerta também para que a medida socioeducativa deve respeitar eticamente a autonomia do adolescente, de acordo com a sua demanda e negando a finalidade pedagógica que representa uma postura totalitária, destruindo a subjetividade

\footnotetext{
${ }^{6}$ Além disso, o exame psiquiatrico permite dobrar o delito, tal como é qualificado pela lei, com toda uma série de comportamentos, de maneiras de ser que, bem entendido, no discurso do perito psiquiatra, são apresentadas como a causa, a origem, a motivação, o ponto de partida do delito. De fato, na realidade da prática judiciária, elas vão constituir a substância, a própria matéria punível. (FOUCAULT, 2001. p. 23).

${ }^{7}$ E assim bradou o personagem em frente aos rebelados contra as massivas internações na Casa Verde: “Meus senhores, a ciência é coisa séria, e merece ser tratada com seriedade. Não dou razão aos meus atos de Alienista a ninguém, salvo aos meus mestres e a Deus. (ASSIS, 1998, p. 64).
} 
do adolescente, o que, para o autor, transforma a atuação da Justiça da Infância e da Juventude em uma função de maternagem ilimitada:

A medida socioeducativa, ou seja, a resposta estatal brasileira, ao promover uma finalidade pedagógica, fomenta a normatização e a disciplina (Foucault), no que pode ser chamado de "McDonaldização" das medidas socioeducativas, a saber, por propostas padrões que desconsideram, por óbvio, o sujeito e, especialmente, a existência de demanda. (ROSA, 2008).

O autor entende que a medida socioeducativa não deve ser uma cruzada pela salvação moral do sujeito, não sendo uma postura democrática pretender melhorá-lo, piorálo nem modificá-lo, devendo:

\footnotetext{
...respeitar o sujeito e com ele, se houver demanda, construir um caminho, sempre impondo sua responsabilidade pelo ato e o relembrando, ou mesmo advertindo, de que existe algo de impossível, algo que se não pode gozar. Nem nós, nem eles. A cruzada pela salvação moral é estranha à democracia, como o inconsciente o é do orgulhoso cidadão da Modernidade. (ROSA, 2008).
}

A ideia de normalização do sujeito, de cura e de modificação remonta à visão positivista que explica as causas da delinqüência em características físicas do indivíduo, que necessita de contenção e intervenção, para proteger a sociedade e a si mesmo de seus atos anti-sociais, como refere Mario Volpi:

\begin{abstract}
Formulada perversamente como categoria pretensamente científica, advoga que a índole, isto é, a tendência, a motivação interna, o caráter e a personalidade do individuo apresentam a propensão à pratica do mal, no nosso caso, do delito. Originada da constituição de perfis e modelos comportamentais que produziram o infrator, apresenta-o como um monstro maléfico a ser combatido por punições severas ou tratamentos terapêuticos de alta intensidade. (VOLPI, 2001, p. 19-20).
\end{abstract}

\title{
4. O paralelo entre o médico e o juiz: o alienista e o alienado
}

O próprio Alienista reconhece que a diferença é o que há de mais normal na loucura do ser humano. Não por outro motivo desinternou todos os loucos e passou a "meter na Casa Verde" somente aqueles que detivessem perfeito equilíbrio mental e moral (ASSIS, 1998, p. 78), e, passados cinco meses depois de curados até mesmo os completamente equilibrados, Simão Bacamarte chega ao ápice de sua própria desconstrução: 
Isso é isto. Simão Bacamarte achou em si os característicos do perfeito equilíbrio mental e moral; pareceu-lhe que possuía a sagacidade, a paciência, a perseverança, a tolerância, a veracidade, o vigor moral, a lealdade, todas as qualidades enfim que podem formar um acabado mentecapto. (ASSIS, 1998, p. 85).

Obviamente também não se trata de ignorar a existência de atos infracionais graves cometidos de acordo com os dados analisados, bem como que muitos deles foram praticados inclusive com requintes de crueldade dignos de histórias de horror. No entanto, tratam-se de atos infracionais, não de adolescentes, visto que não se pode conceituar o indivíduo como bom ou mal, muito menos partir da premissa de que a pobreza e a carência absoluta são as causas originárias e únicas para o cometimento de um delito ${ }^{8}$.

Não se pode mais utilizar o modelo de explicação da criminalidade do tipo Robin Hood, que rouba dos ricos para dar aos pobres (ZALUAR, 2004, p. 60).

\begin{abstract}
A imagem do menino de ruas faminto, que rouba para comer torna-se o modelo explicativo para o pandemônio instalado nas cidades brasileiras. Não se perguntou por que, em pouco tempo, ao final dos anos 1970, esses meninos passaram a formar bandos ou galeras para brigar entre si nos bailes, nem por que apenas uma pequena minoria acabou juntando-se às quadrilhas para seguir carreiras criminosas de ladrões e traficantes. (ZALUAR, 2004, p. 58).
\end{abstract}

\title{
5. Considerações finais
}

O que se entendeu é que não se mostraram adequadas as medidas socioeducativas aplicadas com base na finalidade pedagógica, ressocializadora, que tenham fundamentado a aplicação da medida no caso concreto para a proteção (no sentido literal da palavra) do adolescente, ou pela sua periculosidade (constatada via laudo técnico), para reestabelecer os valores éticos e sociais rompidos com o ato delituoso, porque violam o caráter ético proposto pelo paradigma, no sentido do reconhecimento da alteridade do adolescente acusado e eventualmente condenado pela prática de ato infracional.

\footnotetext{
${ }^{8}$ Em nenhum momento está se baseando, aqui, em uma simples correlação entre causa e conseqüência, como se o crime fosse apenas o produto da pobreza. 
Mais uma vez reitera-se que não se está a negar a gravidade de determinados atos infracionais praticados, entretanto, alertar sobre o alto grau de seletividade inerente aos processos analisados. Além da densa organização da Justiça da Infância e da Juventude no tratamento do adolescente acusado da prática de ato infracional ${ }^{9}$ fica evidente pela análise das sentenças que existe um estereótipo de adolescente a ser selecionado.

Isto porque, como anteriormente ressaltado, a grande maioria das internações no Brasil é determinada aos adolescentes que preenchiam os caracteres subjetivos de seleção, ocorrendo a criminalização conforme o estereótipo (ZAFFARONI, 2003, p. 49), existindo casos em que a gravidade inerente ao delito não se mostrou tão relevante para justificar a segregação ${ }^{10}$, havendo uma predominância de maior rigor em atos infracionais contra o patrimônio.

O alarmante número de medidas socioeducativas de internação de adolescentes no Brasil pode se comparar à generalização de internações de cidadãos na Casa Verde. Na obra, Machado de Assis conta que mais de $4 / 5$ da população de Itaguaí fora considerada padecente de algum tipo de loucura, tendo o médico determinado inclusive a internação de sua própria esposa (ASSIS, 1998, p. 75-76).

Muito embora todo o equívoco do médico, que inicialmente internou $4 / 5$ da população e após acreditou que loucos eram os que possuíam maior equilíbrio, pois a regra é a loucura e a normalidade é a exceção, e por esta razão mesma se torna a loucura, o Alienista, sofrendo o ataque de sua própria autocrítica, faz a si mesmo a desconstrução que falta ao juiz, caso contrário, "Quem nos protege da bondade dos bons?" (MARQUES NETO, 1994, p. 50).

\section{REFERÊNCIAS BIBLIOGRÁFICAS}

ANDRADE, Vera Regina Pereira de. A ilusão da segurança jurídica - do controle da violência à violência do controle penal. Porto Alegre: Livraria do Advogado, 1997.

\footnotetext{
${ }^{9}$ A Justiça da Infância e da Juventude se institucionaliza de um modo complexo, com diversos meios de resolução do conflito nascido com a pratica do ato infracional. Ainda que se desconsidere toda a seletividade naturalmente existente, neste caso em particular verificamos que o adolescente ainda será submetido à possibilidade de receber a remissão pelos atos cometidos, segundo critérios estabelecidos pelo Ministério Público ou pelo juiz da justiça Instantânea.

${ }^{10}$ Resultados de pesquisa realizada perante às Varas da Infância e da Juventude de Porto Alegre no ano de 2007. A investigação foi realizada em sede de Dissertação de Mestrado em Ciências Criminais pela autora.
} 
ASSIS, Machado de. O Alienista. Contos Escolhidos. São Paulo: Klick Editora, 1998.

PAULA, Paulo Afonso Garrido de. Ato infracional e natureza do sistema de responsabilização. Justitia. Disponível em: www.ilanud.org.br/pdf/book_just_adol_ato_infrac.pdf. Acesso em 03 mar. 2013.

FOUCAULT, Michel. Os Anormais. São Paulo: Martins Fontes, 2001.

LARRAURI, Elena. La Herencia de la criminología crítica. Cerro Del Água: Siglo Veintuno de España Editores, sa: Madrid, e Siglo Veintuno editores, sa, 2000.

MARQUES NETO, Agostinho Ramalho. O poder Judiciário na Perspectiva Democrática - O juiz cidadão. Revista ANAMATRA, v. ,n., pp. xx-xx, 1994.

ROSA, Alexandre Morais da. Adolescentes, ato infracional e maternagem ilimitada. 2006. Disponível em http://www.ibdfam.org.br/?artigos\&artigo=210. Acesso em 04 abr. 2013. ROSA, Alexandre Morais da. Introdução crítica ao ato infracional. Princípios e garantias constitucionais. Rio de Janeiro: Lumen Juris, 2007.

SANTOS, Juarez Cirino dos. O adolescente infrator e os direitos humanos. Disponível em: www.cirino.com.br. Acesso em 06 fev. 2013.

VOLPI, Mario. Sem liberdade, sem direitos. A privação de liberdade na percepção do adolescente. São Paulo: CORTEZ, 2001.

ZALUAR, Alba. Integração Perversa: pobreza e tráfico de drogas. Rio de Janeiro: FGV, 2004.

ZAFFARONI, Eugenio Raul; BATISTA, Nilo. Direito Penal Brasileiro - I. Rio de Janeiro: Revan, 2003. 